\title{
The effect of the preoperative anaesthesiological interview on the levels of stress and anxiety of the heart surgical patient
}

\author{
Androula C. Karaolia ${ }^{1}$, Georgios I. Tagarakis ${ }^{2}$, Elena Argyriadou ${ }^{3}$, Ilias Bonotis ${ }^{4}$, Ioannis Alexiou ${ }^{2}$, \\ Nikolaos Tsilimingas ${ }^{5}$ \\ 1- Anaesthesiology Department, University Hospital of Larissa, University of Thessaly, Greece \\ 2- Department of Cardiothoracic Surgery, AHEPA Hospital, Aristotle University of Thessaloniki, Greece \\ 3- Department of Anaesthesiology, AHEPA Hospital, Aristotle University of Thessaloniki, Greece \\ 4- Department of Psychiatry, University Hospital of Larissa, Greece \\ 5- Department of Cardiothoracic Surgery, University Hospital of Larissa, University of Thessaly, Greece \\ Corresponding Author Georgios I. Tagarakis, MD, MSc, Dsc, FECTS, Assistant Professor of Cardiothoracic \\ Surgery, Aristotle University of Thessaloniki, Greece \\ E-mail gtagarakis@gmail.com, tel 00306970806717
}

\begin{abstract}
Background. Stress and Anxiety are commonly observed before major surgical procedures, such as heart surgical operations. Aim of the current study is to investigate the effect of the preoperative anaesthesiological interview on these parameters. Methods. We prospectively included in the study 152 patients planned to undergo elective heart surgery. All patients were examined with the State-Trait anxiety inventory (STAI) scale on admission and again before surgery (prior to the anaesthesiological interview for the control group and after the latter for the intervention group). Results. Members of the control group had significantly higher levels of stress based on the test results, on the day prior to surgery. On the contrary, the members of the intervention group had significantly lower levels of stress on the same day. Conclusions. The anaesthesiological interview has a positive influence as it lowers the preoperative levels of stress and anxiety.
\end{abstract}

\section{INTRODUCTION}

Submission to a major surgical procedure consists a major cause of stress and anxiety both for the patient as well as for his nearest relatives and friends. Submission to a heart surgical procedure is an example of such a stressful event, as the organ target of surgery is one of the vital organs of the human body, whose proper function is connected with the very existence of every human being [1].

Apart from the danger of death, heart surgical procedures are associated with a considerable morbidity, which includes complications like acute perioperative heart infarct, stroke, delirium, cognitive decline, renal failure, intestinal ischemia and others [1-5]. These complications, although in decline during the last decades, are still an existing possibility. In addition, these complications are more or less known among the general population, but especially among heart patients planned to undergo an elective heart surgical procedure, both through the informative discussion with physicians, as well as through each patient's own research through printed medical literature or the internet.

As stress and anxiety are factors that may play a negative role in the patients postoperative course, $[6,7,8]$, we decided to investigate the effect of the anaesthesiological interview with the patient prior to surgery on the level of stress and anxiety of the heart surgical patients in the preoperative phase.

\section{METHODS}

We prospectively included in the study 152 patients planned to undergo elective heart surgery at the Cardiothoracic Department of the University of Thessaly, in Larissa, Greece. Recruitment period was between 2012 and 2015. All patients were examined on admission with the neuropsychological test. The patients were then divided randomly into two groups. The first one was submitted to the same neuropsychological test on the day before surgery and after the official inclusion of the patient's name into the operative schedule, prior to the interview with the member of the anaesthesiology staff. The second group was submitted to the same test also upon announcement of the operative schedule but after the interview with the anesthesiology nurse. The same anaesthesiological nurse (AK) performed the interview with all the patients.

\section{The neuropsychological test}

\section{The State-Trait anxiety inventory (STAI)}

The State-Trait Anxiety Inventory (STAI) is a self-report measurement scale of anxiety developed by Spielberger in the early 1970s and also is the research instrument with the greatest impact in the history of anxiety measurement. It has been justifiably characterized as "Gold Standard" because the validity of every new method has to be compared with STAI [9]. Unlike the vast majority of the other subjective methods, the uniqueness of STAI is based on the fact that it distinguishes between state and trait anxiety. State anxiety stands for a current condition of anxiety due to temporary situations, while trait anxiety is a principle of personality and corresponds with a generalized inclination to be anxious. In order to study the stressful affection of a current medical condition on the patient a researcher must isolate the anxiety due to the pre-mentioned condition from anxiety due to other permanent sources $[10,11,12]$. In 1983 Spielberger revised initial STAI (X form) to the newer form $Y$ which discriminates effectively between anxiety and depression [13]. 


\section{Description}

STAI consists from two components. The first scale (items 1-20) measures state anxiety (STAI-S) focusing on subjective feelings of apprehension, tension, nervousness and worry while the other scale (items 21-40) measures trait anxiety (STAI-T) evaluating general state of calmness, confidence, and security. Responders have to answer each question by choosing from a 1 to 4 scale depending on the severity of their anxious feelings. The whole test requires about 10 minutes to complete. Possible answers for STAI-S are 1) not at all, 2) somewhat, 3) moderately so, and 4) very much so. Respectively the answers for STAI-T are 1) almost never, 2) sometimes, 3) often, and 4) almost always. The STAI is offered from the publisher, Mind Garden, 855 Oak Grove Avenue, Suite 215, Menlo Park, CA 94025 (URL: http://www.mindgarden. com/index.htm.) and it has been translated in dozens of languages throughout the world. The Greek version was released in 1984 and corresponds to the newer form Y. It has been sufficiently tested proving high reliability and validity with satisfactory item remainder correlations, test retest reliability and discriminant validity [14].

\section{Scoring}

After reversing scores for positively worded items the score of each component of the test is calculated by adding the item scores. The range of score is $20-80$. The higher the score the greater the anxiety. Despite the obvious and clinically tested cut point of 40 , some studies have suggested a cut point of 55. The high validity and reliability of STAI also in comparison with other scales has been multiply confirmed in hundreds of published studies [14-21].

\section{Statistical methods}

The $\mathrm{x}^{2}$ criterion was used for the comparison of categorical parameters between the two groups of patients. The t-student criterion (unpaired) was applied for the comparison of continuous parameters between the groups. The comparison of percentages and the t-student (paired) were applied to detect statistical differences in the test results between the two groups.

The level of statistical significance was set to the threshold of $p<0.05$. The statistical package used was the IBM SPSS, version 21.0 .

\section{RESULTS}

There were no significant differences between the two groups in regard to the basic demographic parameters, which included age, gender and years of education. There was no significant difference between the two groups in regard to the kind or procedure (CABG-non CABG). More specifically, mean age was $65.88 \pm 10.8$ years for the control group and $66.67 \pm 9.7$ years for the intervention group. The analogy of the female gender was 12 out of 76 patients (15.78\%) in the control group and 10 out of 76 patients $(13.15 \%)$ in the intervention group, non significant difference. Patients of the control group had $8.55 \pm 3.09$ years of education, while patients of the intervention group had $8.1 \pm 3.12$ years of education. The vast majority of both groups were Greek nationals (73 out of $76-96.05 \%$ vs 74 out of $76-96.37 \%$ ), non significant difference. In total, 56 out of 76 patients (73.68\%) of the control group were submitted to CABG, while 58 out of 76 patients of the intervention group were submitted to CABG $(76.31 \%)$, non significant difference.

Patients of the control group had a mean test score of $87.34 \pm 17.72$ points on admission and a mean test score of $99.13 \pm 15.65$ points on the second examination. This corresponds to an increase of $11.89 \%(p<0.05)$. Patients of the intervention group had a mean test score of $96.02 \pm 17.82$ points on admission and a mean test score of $79.63 \pm 15.76$ points on the second examination, which occurred after the anesthesiologists interview. This corresponds to a decrease of $17.13 \%(p<0.001)$. The alteration in the test results between test 1 and test 2 between the two groups was statistically significant $(p<0.001)$. The aforementioned data are depicted on Table 1.

\section{CONCLUSIONS AND DISCUSSION}

Stress and anxiety consist two major burdening factors for patients undergoing heart surgery. They have been associated with augmented frequency of postoperative cognitive decline, postoperative delirium and with a prolonged hospital stay $[1,2,3]$. In the current study we aimed to prove the effect of the anaesthesiological interview on the level of stress and anxiety of preoperative patients, planned for elective heart surgery. The general anesthesia itself consists one of the major problems related to the whole procedure as seen by the patient's point of view.

The results of the study for the control group have shown an increased level of stress and anxiety as the procedure was approaching and the patients faced the fact that their name was officially on the operative schedule. On the contrary, the results for the intervention group have shown that after the intervention of the anaesthesiologist the levels of stress and anxiety as measured by the neuropsychological test declined to a significant extent, which is an indication or proof that this interview relaxes the patient, possibly through both the human contact with a responsible member of the operative staff, but also through the better understanding of the whole procedure, as the interview is planned to inform and answer to questions of a general or sometimes very practical nature that trouble the patient.

These results support the necessity of the anaesthesiological interview prior to heart surgery and also the need for a thorough, detailed and without any time pressure discussion between the anesthesiologist or the anaesthesiological nurse and the patient. In the times of computerized and technology-based practice of medicine, this reminds us of the importance of the personal contact between a patient and his healer. 


\section{REFERENCES}

1. Goncalves KK, Silva JI, Gomes ET, Pinheiro LL, Fiqueiredo TR, Bezerra SM. Anxiety in the preoperative period of heart surgery. Rev Bras Enferm. 2016 Mar-Apr; 69(2):397-403

2. Fathi M, Alavi SM, Joudi M, Joudi M, Mahdikhani H, Ferasatkish R et al. Preoperative anxiety in candidates for heart surgery. Iran J Psychiatry Behav Sci. 2014 Summer;8(2):90-6

3. Caumo W, Schmidt AP, Schneider CN, Bergmann J, Iwamoto CW, Bandeira D, Ferreira MB. Risk factors for preoperative anxiety in adults. Acta Anaesthesiol Scand. 2001 Mar;45(3):298-307

4. Burkauskas J, Brozaitiene J, Bunevicius A, Neverauskas J, Zaliunaite V, Bunevicius R. Association of Depression, Anxiety, and Type D Personality with Cognitive Function in Patients with Coronary Artery Disease. Cogn Behav Neurol. 2016 Jun;29(2):91-9

5. Chikwe J, Cooke D, Weiss A. Oxfords Handbook of Cardiothoracic Surgery, Second Edition, 2013

6. Neupane I, Arora RC, Rudolph JL. Cardiac surgery as a stressor and the response of the vulnerable older adult. Exp Gerontol. 2016 Apr 26

7. Poole L, Ronaldson A, Kidd T, Leigh E, Jahangiri M, Steptoe A. Pre-surgical depression and anxiety and recovery following coronary artery bypass graft surgery. J Behav Med. 2016 Aug 23

8. Kok L, Sep MS, Veldhuijzen DS, Cornelisse S, Nierich AP, van der Maaten J et al. Trait anxiety mediates the effect of stress exposure on post-traumatic stress disorder and depression risk in cardiac surgery patients. J Affect Disord. 2016 Jul 21;206:216-223

9. Kain ZN, Mayes LC, Cicchetti DV, Bagnall AL, Finley JD, Hofstadter MB. The Yale Preoperative Anxiety Scale: How Does It Compare with a "Gold Standard"? Anesth Analg 1997; 85: 783-788.

10. Spielberger CD, Gorsuch RL, Lushene RE. Test manual for the State Trait Anxiety Inventory. Palo Alto, California: Consulting Psychologists Press, 1970.

11. Spielberger CD. Assessment of state and trait anxiety: conceptual and methodological issues. Southern Psychologist 1985; 2: 6-16.

12. Julian Laura. Measures of anxiety. Arthrit Care Res 2011; 63: S467-S472.

13. Spielberger CD. Manual for the State-Trait Anxiety Inventory (Form Y). Palo Alto, California: Consulting Psychologists Press, 1983.

14. Fountoulakis KN, Papadopoulou M, Kleanthous S, et al. Reliability and psychometric properties of the Greek translation of the State-Trait Anxiety Inventory form Y: Preliminary data. Ann Gen Psychiatry 2006; 5: 2.

15. Knight RG, Waal-Manning HJ, Spears GF. Some norms and reliability data for the State-Trait Anxiety Inventory and the Zung Self-Rating Depression scale. Br J Clin Psychol 1983; 22 Pt 4:245-9.

16. Addolorato G, Ancona C, Capristo E, Graziosetto R, Di Rienzo L, Maurizi M, et al. State and trait anxiety in women affected by allergic and vasomotor rhinitis. J Psychosom Res 1999;46: 283-9.

17. Kvaal K, Ulstein I, Nordhus IH, Engedal K. The Spielberger State-Trait Anxiety Inventory (STAI): the state scale in detecting mental disorders in geriatric patients. Int J Geriatr Psychiatry 2005;20: 629-34.

18. Bauer C, Rimmele T, Duclos A, Prieto N, Ceika JC, Carry PY et al. Anxiety and stress among anaesthesiology and critical care residents during high-fidelity simulation sessions. Anaest Crit Care Pain Med. 2016 Apr 29

19. Musa C, Kostogianni N, Lepine JP. [The Fear of Negative Evaluation scale (FNE): psychometric properties of the French version]. Encephale. 2004 Nov-Dec;30(6):517-24

20. Newham JJ, Westwood M, Aplin JD, Wittkowski A. State-trait anxiety inventory (STAI) scores during pregnancy following intervention with complementary therapies. J Affect Disord. 2012 Dec 15;142(1-3):22-30

21. Marteau TM, Bekker $\mathrm{H}$. The development of a six-item short-form of the state scale of the Spielberger State-Trait Anxiety Inventory (STAI). Br J Clin Psychol. 1992 Sep;31( Pt 3):301-6 
Table 1. Comparative information of the two Groups

\begin{tabular}{|c|c|c|c|c|}
\hline & Control Group & Intervention Group & & $\begin{array}{l}\text { Statistical } \\
\text { Significance }\end{array}$ \\
\hline Age (Years) & $65.88 \pm 10.8$ & $66.67 \pm 9.7$ & & n.s \\
\hline Gender (Female) & 12 out $76(15.78 \%)$ & $\begin{array}{l}10 \text { out of } 76 \\
(13.15 \%)\end{array}$ & \multicolumn{2}{|l|}{ n.s. } \\
\hline Years of Education & $8.55 \pm 3.09$ & $8.1 \pm 3.12$ & \multicolumn{2}{|l|}{ n.s. } \\
\hline $\begin{array}{l}\text { Type of procedure } \\
\text { (CABG) }\end{array}$ & $\begin{array}{l}56 \text { out of } 76 \\
(73.68 \%)\end{array}$ & $\begin{array}{l}58 \text { out of } 76 \\
(76.31 \%)\end{array}$ & \multicolumn{2}{|l|}{ n.s } \\
\hline Nationality (Greek) & $\begin{array}{l}73 \text { out of } 76 \\
(96.05 \%)\end{array}$ & $\begin{array}{l}74 \text { out of } 76 \\
(97.36 \%)\end{array}$ & \multicolumn{2}{|l|}{ n.s. } \\
\hline Test Score 1 & $87.34 \pm 17.72$ & $96.02 \pm 17.82$ & \multirow{3}{*}{$11.89 \%$} & \\
\hline Test Score 2 & $99.13 \pm 15.65$ & $79.63 \pm 15.76$ & & \\
\hline $\begin{array}{l}\text { Increase Between } \\
\text { Test Score } 1 \text { and } 2 \\
\text { in the Control } \\
\text { Group }\end{array}$ & & & & $p<0.05$ \\
\hline $\begin{array}{l}\text { Decrease Between } \\
\text { Test } 1 \text { and Test } 2 \\
\text { in the Intervention } \\
\text { Group }\end{array}$ & & & $17.13 \%$ & $p<0.001$ \\
\hline $\begin{array}{l}\text { Comparison of the } \\
\text { differential results } \\
\text { between the two } \\
\text { Groups }\end{array}$ & $11.89 \%$ & $17.13 \%$ & & $p<0.001$ \\
\hline
\end{tabular}

Table 1. The table depicts both demographic data as well as statistical information regarding the two comparison groups. The $\mathrm{x}^{2}$ criterion was used for the comparison of categorical parameters between the two groups of patients. The t-student criterion (unpaired) was applied for the comparison of continuous parameters between the groups. The comparison of percentages and the t-student (paired) were applied to detect statistical differences in the differential test results between the two groups. The level of statistical significance was set to the threshold of $p<0.05$

\section{Notes}

1. n.s-non significant

2. CABG- coronary artery bypass graft operation 